\title{
Family Members: The Forgotten Players in the Diabetes Care Team (The TALK-HYPO Study)
}

\author{
Alexandria Ratzki-Leewing · Ehsan Parvaresh Rizi · Stewart B. Harris
}

Received: July 12, 2019 / Published online: September 9, 2019

(C) The Author(s) 2019

\begin{abstract}
Introduction: The objective of this study was to establish the burden of hypoglycemia on family members of people with diabetes (PWDs) and to gain an understanding of how conversations about hypoglycemia can contribute to diabetes care.

Methods: This was a multinational cross-sectional study of family members of people with type 1 or type 2 diabetes taking insulin and/or secretagogues for $\geq 12$ months who voluntarily completed an online questionnaire.
\end{abstract}

Enhanced Digital Features To view enhanced digital features for this article go to https://doi.org/10.6084/ m9.figshare.9638876.

Electronic supplementary material The online version of this article (https://doi.org/10.1007/s13300019-00687-y) contains supplementary material, which is available to authorized users.

A. Ratzki-Leewing

Department of Epidemiology and Biostatistics,

Schulich School of Medicine and Dentistry, Western

University, London, ON, Canada

E. Parvaresh Rizi

Novo Nordisk, Søborg, Denmark

S. B. Harris $(\bowtie)$

Department of Family Medicine, Schulich School of

Medicine and Dentistry, Western University,

London, ON, Canada

e-mail: stewart.harris@schulich.uwo.ca
Results: Overall, 4300 family members of PWDs (type 1 [29\%], type 2 [46\%], unknown [25\%]) were surveyed. Two in three family members (66\%) reported thinking about the hypoglycemia of the PWD at least monthly, and $64 \%$ felt worried or anxious about the PWD's risk for hypoglycemia. There was general agreement among family members that more conversations about hypoglycemia would have a positive impact on the PWD's life (76\%).

Conclusions: Hypoglycemia can present a burden on the lives of family members of PWDs. Conversations about hypoglycemia, facilitated by a healthcare professional, may reduce this burden and hypoglycemia risk.

Funding: Novo Nordisk A/S.

Keywords: Clinical care; Hypoglycemia; Insulin; Secretagogue; Type 1; Type 2

\section{INTRODUCTION}

Family support is an important resource for a person with diabetes (PWD) [1]. However, little is known about the familial burden and distress induced when a family member with diabetes experiences iatrogenic hypoglycemia [2], a treatment-limiting adverse event $[3,4]$ with potentially devastating effects on a PWD's physical health and quality of life [5, 6].

Conversations focused on a discussion of hypoglycemia may mitigate the impact of 
hypoglycemia on PWDs and their family members, helping to optimize and buttress the roles of family members as key assets to healthcare professionals (HCPs) in the management of hypoglycemia.

This real-world, multi-national study (TALKHYPO) leverages the methodological advantages of participant-reported outcomes to investigate specifically how, and to what extent, hypoglycemia affects family members of PWDs taking insulin and/or secretagogues, and the potential benefit of hypoglycemia-specific conversations in diabetes management.

\section{METHODS}

This cross-sectional study involved the design and dissemination of a 47-item online questionnaire across nine countries (Canada, Denmark, France, Germany, Italy, Japan, Spain, UK and USA; disseminated in local languages) between 8 April and 6 May 2019 via Ipsos Healthcare (Electronic Supplementary Materials [ESM]). Participants in the TALK-HYPO study were sampled from pre-existing panels of the general public, with sampling managed by Dynata (Plano, TX, USA) and Userneeds (Copenhagen, Denmark). The panel was formed using multisource recruitment methods (via online banners, e-mails, apps, social media and websites); all panelists must have opted into receiving survey invitations and taking part in the online research.

Individuals aged $\geq 18$ years who identified themselves as family members of adults ( $\geq 18$ years) with type 1 or type 2 diabetes taking insulin and/or secretagogues for $\geq 12$ months prior to the respondent completing the questionnaire were eligible to enroll in the study. Family members were a partner/ spouse, parent, step-parent, grandparent, grandchild, child, step-child, sibling, aunt, uncle, niece, nephew, cousin, or other family member. Members of the pre-existing panels were contacted via e-mail to complete a TALKHYPO screening questionnaire to assess their suitability to participate in the survey (see ESM). Eligible respondents were then asked to provide informed consent in the form of a button (see
ESM for consent text) prior to receiving a link to complete the TALK-HYPO questionnaire. A sample size of 4300 eligible responders was determined a priori $[n=500 /$ country, with the exception of Denmark $(n=300)]$. Data from family members surveyed in Denmark were weighted to 500 respondents.

The aim of the self-administered TALK-HYPO questionnaire was to capture background information on the respondent and their PWD, participant-reported data on experiences of hypoglycemia-specific burden and the impact of conversations on diabetes management. An information page within the questionnaire provided descriptions of daytime mild/moderate hypoglycemic events, severe daytime hypoglycemic events and nocturnal hypoglycemic events and is presented in Table 1.

Due to the nature of this study (online questionnaire), exemption of ethics approval was requested and received by the Pearl international review board (Indianapolis, IN, USA). For that same reason, the study was not registered.

\section{RESULTS}

\section{Demographics and Characteristics}

The total target sample size $(N=4300)$ was achieved, with $29 \%$ of participants being a family member of a person with type 1 diabetes and $46 \%$ of a person with type 2 diabetes; $25 \%$ of respondents did not know the type of diabetes of the PWD. Most respondents were parents/step-parents (37\%) or spouses/partners $(18 \%)$. The mean respondent age (standard deviation [SD]) was 46.6 (15.2) years, and $48 \%$ were male.

The mean age (SD) of the PWD of respondents was 63.0 (SD 17.9) years, and 55\% were male. Over half of the PWDs (63\%) had experienced at least monthly mild/moderate daytime hypoglycemic episodes. Also on at least a monthly basis, $26 \%$ had experienced severe daytime hypoglycemia and $30 \%$ had experienced nocturnal hypoglycemia (mild/moderate or severe) (Table 2). 
Table 1 Descriptions of hypoglycemia used in the questionnaire

\begin{tabular}{ll}
\hline Hypoglycemia type & Description of hypoglycemia used in the questionnaire \\
\hline $\begin{array}{l}\text { Mild/moderate daytime } \\
\text { hypoglycemia }\end{array}$ & $\begin{array}{c}\text { These events, which occur while your family member is awake, are typically marked by signs } \\
\text { and symptoms such as feeling shaky, sweatiness or chills, irritability, being nervous or } \\
\text { anxious, hunger, weakness, mild confusion, forgetfulness, fast heartbeat, feeling dizzy, and } \\
\text { color draining from the skin } \\
\text { Mild/moderate hypoglycemia can also be checked using a blood glucose monitoring device. If } \\
\text { your family member experiences mild/moderate hypoglycemia, he/she will be able to take } \\
\text { self-action to treat the event. When your family member is capable of treating him/herself, } \\
\text { without the assistance of someone else, it is considered a mild/moderate hypoglycemia } \\
\text { event. Treatment can include taking a glucose tablet, drinking a glass of juice, or eating } \\
\text { something } \\
\text { These events, which occur while your family member is awake, can arise when your family } \\
\text { member's low blood sugar is left untreated and continues to drop. The early signs and } \\
\text { symptoms of severe hypoglycemia typically include blurred vision, difficulty concentrating, } \\
\text { confused thinking, slurred speech, numbness, and/or drowsiness. If the blood glucose stays } \\
\text { low for too long, it can result in seizures, comas, and possibly death. When the symptoms } \\
\text { become so severe that your family member is no longer able to treat themselves, he/she will } \\
\text { require help from somebody else to recover. When the individual absolutely needs the } \\
\text { assistance of someone else to recover, it is considered a severe hypoglycemia event. In this } \\
\text { case, you or somebody else may need to administer a glucagon injection to treat your family } \\
\text { member's severe hypoglycemia event. Emergency medical services may also be called, and } \\
\text { hospitalization is sometimes required } \\
\text { These are events that occur while your family member is sleeping or attempting to sleep. } \\
\text { Nocturnal hypoglycemia is typically marked by signs and symptoms such as vivid dreams/ } \\
\text { nightmares, restless sleep, morning headaches, night sweats, tiredness, irritability/confusion } \\
\text { upon waking, convulsions, and talking/shouting while sleeping. Nocturnal events can be } \\
\text { either mild/moderate or severe }\end{array}$ \\
\hline Nocturnal hypoglycemia
\end{tabular}

One-third of PWDs (34\%) had been hospitalized due to hypoglycemia in the previous 12 months (once $14 \%$, twice $10 \%$, three times $6 \%$, or $\geq$ four times $4 \%$ ).

\section{Burden of Hypoglycemia}

Hypoglycemia was perceived as an important factor in the overall management and treatment of diabetes by $91 \%$ of respondents. Many respondents expressed their commitment to helping manage their PWD's hypoglycemia $(77 \%)$, with $60 \%$ agreeing that it is their responsibility to do so. Specifically, respondents reported being involved in the management of their PWD's hypoglycemia in terms of providing emotional support (71\%); helping to treat mild/moderate hypoglycemia (65\%); helping to prevent the PWD from experiencing hypoglycemia (60\%); treating severe hypoglycemia (59\%); and performing day-to-day hypoglycemia monitoring (51\%).

The PWDs' hypoglycemia directly impacted the life of nearly half of all respondents (42\%). Of those who reported being involved in helping to manage their PWD's hypoglycemia $(n=3800), 48 \%$ reported that it took up too much emotional energy. Two in three 
Table 2 Proportion of respondents reporting hypoglycemia in their person with diabetes by frequency and class of hypoglycemia

\begin{tabular}{|c|c|c|c|c|}
\hline \multirow{2}{*}{$\begin{array}{l}\text { Type of hypoglycemic event and } \\
\text { frequency }\end{array}$} & \multirow{2}{*}{$\begin{array}{l}\text { Total } \\
(N=4300)\end{array}$} & \multicolumn{3}{|l|}{ Diabetes type } \\
\hline & & $\begin{array}{l}\text { Type } 1 \text { diabetes } \\
(n=1226)\end{array}$ & $\begin{array}{l}\text { Type } 2 \text { diabetes } \\
(n=1984)\end{array}$ & $\begin{array}{l}\text { Don't know } \\
(n=1090)\end{array}$ \\
\hline \multicolumn{5}{|c|}{ Mild/moderate daytime hypoglycemia, $n$ (\%) } \\
\hline At least once a month & $2690(63)$ & $873(71)$ & $1175(59)$ & $642(59)$ \\
\hline Less than once a month & $1023(24)$ & $239(19)$ & $574(29)$ & $211(19)$ \\
\hline Don't know & $586(14)$ & $125(10)$ & $243(12)$ & $218(20)$ \\
\hline \multicolumn{5}{|l|}{ Severe daytime hypoglycemia, $n$ (\%) } \\
\hline At least once a month & $1133(26)$ & $388(32)$ & $492(25)$ & $252(23)$ \\
\hline Less than once a month & $2374(55)$ & $669(55)$ & $1167(59)$ & $540(50)$ \\
\hline Don't know & $793(18)$ & $182(15)$ & $331(17)$ & $280(26)$ \\
\hline \multicolumn{5}{|c|}{ Nocturnal hypoglycemia (either mild/moderate or severe), $n$ (\%) } \\
\hline At least once a month & $1283(30)$ & $469(38)$ & $557(28)$ & $255(23)$ \\
\hline Less than once a month & $1914(45)$ & $530(43)$ & $966(49)$ & $418(38)$ \\
\hline Don't know & $1104(26)$ & $239(19)$ & $467(24)$ & 398 (37) \\
\hline
\end{tabular}

respondents (66\%) thought about the PWD's hypoglycemia risk at least monthly, and $43 \%$ reported that it affected their mood, evoking feelings of worry or anxiety (64\%). Other negative emotions among respondents included feelings of powerless (21\%) and fear (20\%).

Hypoglycemia among PWDs also compromised respondents' feelings of independence (35\%) and negatively impacted their social life (29\%). To help manage hypoglycemia, $74 \%$ of the respondents who helped manage their PWD's hypoglycemia ( $n=2852 / 3849)$ spent less time on their own activities. These respondents spent less time on pursuing hobbies/leisure activities (43\%); taking holidays/traveling (40\%); pursuing new interests (39\%); practicing self-care (40\%); or being with other friends/family members (39\%) - or they forwent all or some of these activities entirely. Notably, having less sleep or reducing working hours was reported by one in three (36\%) and one in four $(27 \%)$ respondents, respectively.

\section{Conversations About Hypoglycemia}

Of all respondents, 91\% had conversations about hypoglycemia with their PWD $(n=3925 /$ $4300)$; among these, $45 \%$ initiated the conversation. These respondents felt that hypoglycemia-specific conversations enabled them to understand how they could help manage their PWD's hypoglycemia better (85\%) as well as understand what the PWD was going through (88\%); $83 \%$ also felt that such conversations brought them closer to their PWD (ESM Table S1).

In conversations with HCPs, $78 \%$ of respondents encouraged their PWD to discuss hypoglycemia, with prevention (52\%) and treatment $(47 \%)$ of hypoglycemia being the most 
commonly encouraged topics. Positive outcomes were experienced by $94 \%$ of respondents who discussed hypoglycemia with the HCP ( $n$ $=2758 / 2928$ ). These conversations were perceived to improve the PWD's understanding of how to better manage hypoglycemia $(37 \%)$, of the frequency of blood monitoring required (35\%) and of lifestyle behavior (29\%), as well to increase the feeling of well-being about the treatment $(28 \%)$.

Only $34 \%$ of respondents felt they had regular conversations (about once a week or more often) about hypoglycemia with their PWD. Overall, the majority of respondents agreed that having more conversations about hypoglycemia could lead to a positive impact on the PWD's life $(76 \%)$. The most common barriers to conversations about hypoglycemia between respondents and the PWD were the PWD not wanting to talk about it (43\%); the PWD living too far away (37\%); a lack of confidence or knowledge (33\%); and a feeling that it was not the respondent's role (32\%).

\section{DISCUSSION}

This study highlights the substantial burden which hypoglycemia places on many family members of PWDs. Based on the responses to the survey, conversations about hypoglycemia improved several participant-reported outcomes for family members and their PWDs, and improved integration of the family member in conversations with the HCP about hypoglycemia was associated with positive outcomes for the PWD.

These findings corroborate those of a previous survey that examined the experiences of relatives of PWDs, in which $61.3 \%$ (31.5-86.4\%) stated that they worried about the hypoglycemia risk in PWDs [7]. Similarly, in a questionnaire carried out in Canada $(n=552), 92 \%$ of all significant others of PWDs felt committed to helping manage hypoglycemia of their PWD, and $87 \%$ said they would forgo other things in their lives to help manage hypoglycemia [2]. In the TALK-HYPO study, despite the potential burden, we found that the majority of family members were committed to helping manage their PWD's hypoglycemia.

In general, many family members were the catalyst to conversations occurring between HCPs and PWDs, encouraging their PWDs to discuss prevention and treatment of hypoglycemia, leading to positive outcomes and improving many aspects of the PWD's hypoglycemia management. HCPs should thus be aware of the family member's active involvement in hypoglycemia management and strive to capitalize on their potential contributions to supporting clinical care. Interventions aimed at facilitating the increased frequency of hypoglycemia-specific conversations could promote improved outcomes in diabetes. Our study helps verify the current, though sparse, evidence on conversational barriers in diabetes $[8,9]$; it also identifies several other conversational barriers previously undocumented in the literature.

The strengths of this study include its international scope and use of real-world data, both of which increase the generalizability of the findings. Although previous studies have examined the impact of diabetes care on family members in general terms $[7,10]$, examination of the burden of hypoglycemia has been limited to family members' worries about hypoglycemia. However, the current study includes, for example, understanding which aspects of a family member's life are impacted. Additionally, this is the first study examining in detail the effects of conversations between family members and PWDs in the context of hypoglycemia. This information provides a valuable resource for HCPs to adapt their consultations to help reduce the burden on the family member and thereby enhance their ability to support the PWD. While hypoglycemic events were not confirmed by plasma glucose measurements, real-world data allowed the impact of these events to be examined from the perspective of the family member. Finally, the impact of hypoglycemia in people with type 1 and type 2 diabetes (receiving insulin and/or secretagogues) was considered.

There are potential limitations associated with this study. In particular, selection bias (i.e. due to non-random sampling or non- 
participation) may have arisen to the extent that the study sample of family members of PWDs differed from the general population in ways that influenced hypoglycemia event reporting. For example, family members of PWDs who have experienced severe hypoglycemia, especially where hospitalization was required, may have been more motivated to complete the TALK-HYPO study than those with PWDs who have not experienced severe hypoglycemia or related hospitalization. Thus, despite the rigorous recruitment strategies employed in this study and the high global internet coverage, the observed estimates of hypoglycemia frequency may been artifactually inflated.

However, it should be noted that values presented in the current study are those reported by family members, not PWDs, and may reasonably exceed those estimates documented in previous hypoglycemia studies that rely on PWD disclosure during clinical encounters. Indeed, PWD under-reporting of hypoglycemia (e.g. due to perceived consequences on the PWDs' careers or driver's licenses) has been identified as a major problem in clinical care $[11,12]$. This is further demonstrated by higher observed rates of hypoglycemia in studies that utilize self-reported data as opposed to sourcing data from clinical trial settings [13, 14].

Finally, given the cross-sectional study design, temporality could neither be assessed nor established. Notwithstanding, the primary aims of the TALK-HYPO study were descriptive in nature with the purpose of drawing attention to the alarming effects of hypoglycemia on family members of PWDs and exploring hypoglycemia-related conversations as a possible conduit for improved public health planning and clinical management.

\section{CONCLUSIONS}

This survey of family members of PWDs details the significant burden on many of them that result from helping to manage their PWD's hypoglycemia. Strategic collaboration through conversations between HCPs and family members of PWDs could reduce the burden and risk of hypoglycemia, providing new evidence of the importance of engaging family members in diabetes management.

\section{ACKNOWLEDGEMENTS}

The authors would like to thank the respondents for their involvement in the study.

Funding. This study was sponsored and funded by Novo Nordisk A/S. The journal's Rapid Service Fee was also funded by Novo Nordisk A/S. All authors had full access to all of the data in this study and take complete responsibility for the integrity of the data and accuracy of the data analysis.

Medical Writing and/or Editorial Assistance. Medical writing and editorial support, under the guidance of the authors, was provided by Matthew Robinson and Catherine Jones from Watermeadow Medical, an Ashfield company, part of UDG Healthcare plc, funded by Novo Nordisk.

Authorship. All named authors meet the International Committee of Medical Journal Editors' (ICMJE) criteria for authorship for this article, take responsibility for the integrity of the work as a whole, and have given their approval for this version to be published.

Authorship Contributions. All authors had access to the final results and vouch for the fidelity of the trial to the protocol. All authors contributed to drafting/critically revising the article, approval of the final manuscript and sharing in the final responsibility for the content of the manuscript and the decision to submit it for publication.

Disclosures. Alexandria Ratzki-Leewing has received research grant support from Sanofi and consultancy fees from Novo Nordisk. Ehsan Parvaresh Rizi is a full-time employee of Novo Nordisk A/S. Stewart Harris declares the following: grants, personal fees, member of an advisory board and consultancy fees from Sanofi, Janssen and Abbott; grants, personal fees, 
member of an advisory board, consultancy fees and involvement in clinical studies from Eli Lilly, Novo Nordisk, AstraZeneca and Boehringer Ingelheim; and personal fees, member of an advisory board and consultancy fees from Merck.

Compliance with Ethics Guidelines. Due to the nature of this study (online questionnaire), exemption of ethics approval was requested and approved by the Pearl international review board (Indianapolis, IN, USA). Informed consent was received from participants in the form of a button (see the ESM for consent text) prior to receiving a link to complete the TALK-HYPO study.

Data Availability. The datasets generated during and/or analyzed during the current study are available from the corresponding author on reasonable request.

Open Access. This article is distributed under the terms of the Creative Commons Attribution-NonCommercial 4.0 International License (http://creativecommons.org/licenses/ by-nc/4.0/), which permits any noncommercial use, distribution, and reproduction in any medium, provided you give appropriate credit to the original author(s) and the source, provide a link to the Creative Commons license, and indicate if changes were made.

\section{REFERENCES}

1. Rosland AM, Heisler M, Choi HJ, Silveira MJ, Piette JD. Family influences on self-management among functionally independent adults with diabetes or heart failure: do family members hinder as much as they help? Chronic Illn. 2010;6:22-33.

2. Reichert SM, Ratzki-Leewing A, Ryan BL, et al. Hypoglycemia management through the eyes of the significant other: highlights from the InHypoDM study (Canada). Diabetes. 2017;66:A106.

3. Pawaskar M, Witt EA, Engel SS, Rajpathak SN, Iglay K. Severity of hypoglycaemia and health-related quality of life, work productivity and healthcare costs in patients with type 2 diabetes in Europe. Endocrinol Diabetes Metab. 2018;1:e00011.
4. Brod M, Wolden M, Christensen T, Bushnell DM. A nine country study of the burden of non-severe nocturnal hypoglycaemic events on diabetes management and daily function. Diabetes Obes Metab. 2013;15:546-57.

5. Rossi MC, Nicolucci A, Ozzello A, et al. Impact of severe and symptomatic hypoglycemia on quality of life and fear of hypoglycemia in type 1 and type 2 diabetes. Results of the Hypos-1 observational study. Nutr Metab Cardiovasc Dis. 2019;29:736-43.

6. Giorda CB, Ozzello A, Gentile S, et al. Incidence and risk factors for severe and symptomatic hypoglycemia in type 1 diabetes: Results of the HYPOS-1 study. Acta Diabetol. 2015;52:845-53.

7. Kovacs Burns K, Nicolucci A, Holt RI, et al. Diabetes attitudes, wishes and needs second study (DAWN2): cross-national benchmarking indicators for family members living with people with diabetes. Diabet Med. 2013;30:778-88.

8. Lawton J, Rankin D, Elliott J, et al. Experiences, views, and support needs of family members of people with hypoglycemia unawareness: interview study. Diabetes Care. 2014;37:109-15.

9. Samuel-Hodge CD, Cene CW, Corsino L, Thomas C, Svetkey LP. Family diabetes matters: a view from the other side. J Gen Intern Med. 2013;28:428-35.

10. Nefs G, Pouwer F. The role of hypoglycemia in the burden of living with diabetes among adults with diabetes and family members: results from the DAWN2 study in The Netherlands. BMC Public Health. 2018;18:156.

11. Ostenson CG, Geelhoed-Duijvestijn P, Lahtela J, Weitgasser R, Markert Jensen M, Pedersen-Bjergaard U. Self-reported non-severe hypoglycaemic events in Europe. Diabet Med. 2014;31:92-101.

12. Ratzki-leewing A, Black JE, Mequanint S, et al. Severe hypoglycemia rates are highest among those with suboptimal reporting behaviour-results from the InHypo-DM study. Diabetes. 2018;67:399.

13. Elliott L, Fidler C, Ditchfield A, Stissing T. Hypoglycemia event rates: a comparison between realworld data and randomized controlled trial populations in insulin-treated diabetes. Diabetes Ther. 2016;7:45-60.

14. Ratzki-Leewing A, Black JE, Mequanint S, et al. The "Unspoken" truth: suboptimal reporting of severe hypoglycemia in diabetes (InHypo-DM study). Can J Diabetes. 2018;42:S52-3. 